\title{
Effects of Dietary Citric Acid on Metabolic Indicators and Gene Expression in the Skeletal Muscles of Fasted Mice
}

\author{
Yurie Hara $^{1^{*}}$, Nakamichi Watanabe ${ }^{2}$ \\ ${ }^{1}$ Department of Human Sciences and Design, Graduate School of Showa Women's University, Tokyo, Japan; ${ }^{2}$ Department of Human \\ Health and Design, Showa Women's University, Tokyo, Japan. \\ Email: *12212009@st.swu.ac.jp
}

Received August $4^{\text {th }}, 2013$; revised September $4^{\text {th }}, 2013$; accepted September $11^{\text {th }}, 2013$

Copyright (C) 2013 Yurie Hara, Nakamichi Watanabe. This is an open access article distributed under the Creative Commons Attribution License, which permits unrestricted use, distribution, and reproduction in any medium, provided the original work is properly cited.

\begin{abstract}
Citric acid is recognized and utilized as a dietary supplement for its ability to eliminate fatigue. However, the molecular and cellular mechanism underlying this effect has not been elucidated. This study investigated the effect of intragastric citric acid administration on the energy metabolism and gene expression in the skeletal muscles of mice that had been fasted without exercise, using biochemical analyses of metabolic indicators and DNA microarrays. Expression of the genes involved in the glycolysis, tricarboxylic acid cycle and $\beta$-oxidation of fatty acids were not affected by citric acid administration. However, citric acid increased the level of blood glucose and expression of the phosphoenolpyruvate carboxykinase gene. These results indicate that citric acid ingestion may eliminate fatigue by promoting gluconeogenesis.
\end{abstract}

Keywords: Citric Acid; Fatigue; Gluconeogenesis; DNA Microarray; TCA Cycle

\section{Introduction}

Citric acid has long been recognized for its ability to relieve physical fatigue. Accordingly, citric acid is growing in popularity as a supplement in sports nutrition. For example, intake of citric acid from lemons $(2.7 \mathrm{~g} / \mathrm{day}, 28$ days) was determined to be effective for the reduction of lassitude, stress, and boredom in one investigation [1]. Moreover, sodium citrate ingestion $(0.4 \mathrm{~g} / \mathrm{kg}$ body weight) has been reported to improve muscle performance, as determined by an ergometer, during exercise in humans [2]. Oöpik et al. have suggested that the ingestion of 0.5 $\mathrm{g}$ of sodium citrate $/ \mathrm{kg}$ body mass shortly before a $5 \mathrm{~km}$ running time trial improves performance in well trained college runners [3].

Several hypotheses have been proposed to explain the anti-fatigue effects of citric acid, including: 1) that it suppresses the accumulation of lactic acid in the blood; 2) that it increases ATP production; 3) that it suppresses the production of ketone bodies, a fatigue factor, by curtailing fatty acid $\beta$-oxidation; 4$)$ that it stimulates glycolgenesis. However, the physiological mechanism under-

\footnotetext{
*Corresponding author.
}

lying this anti-fatigue response has not been resolved.

There is sound rationale for each of the proposed hypothesis. For example, suppression of lactic acid build-up in the blood is thought to be achieved when citric acid, produced in the tricarboxylic acid (TCA) cycle, inhibits phosphofructokinase (Pfk), a rate-limiting enzyme of the glycolytic pathway, which in turn limits excess accumulation of pyruvic acid [4-6]. Meanwhile, increased ATP production is believed to occur when citric acid is supplied to the mitochondria, where it accelerates the TCA cycle and the electron transport chain [7]. The suppression of ketone body production from reduced fatty acid $\beta$-oxidation is thought to occur in response to a citricacid induced rise in malonyl CoA. Citric acid is believed to stimulate malonyl CoA production by increasing the activity of acetyl-CoA carboxylase, an enzyme that converts acetyl CoA to malonyl CoA [4]. The rise in malonyl CoA inhibits carnitine palmitoyltransferase in the inner membrane of the mitochondria, which then impairs the transport of fatty acids into the mitochondria. In addition, stimulation of glycogenesis was shown using in vitro experiments on rat skeletal muscle and livers. In these experiments, an increase in the concentration of 
glucose-6-phosphate, resulting from a citric-acid induced rise in hexokinase activity, inhibited Pfk, a rate-limiting enzyme of the glycolytic pathway [5].

Despite physiological evidence that citric acid is able to reduce or eliminate fatigue, the underlying molecular mechanism and cellular pathways responsible for this effect remain unresolved. The aim of this study was to investigate the cellular and molecular effects of citric acid ingestion on energy metabolism pathways of skeletal muscle. We looked at the early changes in the expression of genes involved in these pathways by using a combination of biochemical and DNA microarray analyses.

\section{Materials and Methods}

\subsection{Animals and Experimental Design}

Eight-week-old male C57BL/6J mice were purchased from Charles River Laboratories, Japan Inc. The mice were kept in individual plastic cages at $23^{\circ} \mathrm{C} \pm 2^{\circ} \mathrm{C}$ with a 12-hour light-dark cycle (light from 8 a.m. to 8 p.m.). After mice were maintained for one week on commercial, non-purified chow diet (CRF-1: Charles River Laboratories Japan Inc.), they were divided equally into a distilled water ingestion group (control) and a citric acid ingestion group $(\mathrm{n}=3)$. The mean weights of the control and treatment groups were equal. After 20 hours of fasting, the mice were deprived of water for 2 hours, after which distilled water or a citric acid solution $(20 \mathrm{mg} / 30 \mathrm{~g}$ body weight) was administered intragastrically with a probe. Forty minutes after administration the mice were sacrificed by decapitation and samples of their blood and skeletal muscle (soleus and gastrocnemius muscles) were collected. The blood samples were used to measure blood glucose and lactic acid, and an aliquot was centrifuged $(10000 \times \mathrm{g}, 5 \mathrm{~min})$ to obtain plasma. The plasma was frozen and stored at $-30^{\circ} \mathrm{C}$ until it was analyzed to determine the citric acid concentration. The skeletal muscles were sampled for microarray analysis, immediately immersed in RNA later and submitted for analysis. This study was approved by the experimental animal ethics committee of Showa Women's University and was conducted according to the experimental animal.

\subsection{Microarray Analysis}

DNA microarray analysis was conducted by a DNA Chip Research Inc. This analysis was performed on pooled total RNA isolated from the muscle samples of three animals.

\subsection{Measurement of Plasma Citric Acid Level}

An improvement on the method of Yasukawa et al. [8,9] was used to measure plasma citric acid concentration.
Briefly, $500 \mu \mathrm{L}$ of $6 \%$ perchloric acid to $250 \mu \mathrm{L}$ plasma, incubated at room temperature for 5 minutes, then centrifuged $(10000 \times \mathrm{g}, 5 \mathrm{~min})$ to obtain a deproteinized supernatant. Of this supernatant, $500 \mu \mathrm{L}$ was neutralized with approximately $150 \mu \mathrm{L}$ of $2 \mathrm{~N} \mathrm{KOH}$, after which 350 $\mu \mathrm{L}$ of $1.2 \mathrm{M} \mathrm{KCl} / 1 \mathrm{M}$ Tris $\mathrm{HCl}$ buffer $(\mathrm{pH} 8.6)$ was added, and the mixture was centrifuged $(10000 \times \mathrm{g}, 5 \mathrm{~min})$. Next, $500 \mu \mathrm{L}$ of this supernatant was collected, $500 \mu \mathrm{L}$ of reagent ( $1 \mathrm{M}$ Tris $\mathrm{HCl}$ buffer $\mathrm{pH} 8.60 .025 \mathrm{~mL} /$ sample, $0.4 \mathrm{mM}$ ZnSO4 $0.25 \mathrm{~mL} / \mathrm{sample}, \beta$-NADH $0.2 \mathrm{~mL} / \mathrm{sample}$, MDH $0.025 \mathrm{~mL} / \mathrm{sample}$ ) was added and samples were incubated for 5 minutes at room temperature. Samples were then divided into 2 portions and $20 \mu \mathrm{L}$ of solvent $(0.15 \mathrm{M}$ Tris $\mathrm{HCl}$ buffer $\mathrm{pH} 8.6)$ was added to one and $20 \mu \mathrm{L}$ of citrate lyase (CL $0.5 \mathrm{mg} / 0.15 \mathrm{M}$ Tris $\mathrm{HCl}$ buffer $\mathrm{pH}$ 8.6) to the other. The resulting solutions were incubated at room temperature for 20 minutes before the absorbance (at $340 \mathrm{~nm}$ ) was measured with a spectrophotometer. NADH consumption was determined from the difference in absorbance between the two samples and used to calculate the plasma citric acid concentration.

\subsection{Measurement of Blood Glucose and Lactate Levels}

Blood glucose and lactic acid values were measured at the time of dissection. Medisafe Chips (Terumo Corp.) were used to measure blood glucose, and Lactate Pro (Arkray Inc.) was used to measure lactic acid. Manufacturer protocols were followed for each analysis and all measurements were performed in duplicate.

\subsection{Statistical Analysis}

All data was expressed as mean \pm standard error. The student's t-tests were used to examine differences between the two groups in this chapter. Results were considered significant at $\mathrm{P}<0.05$.

\section{Results}

\subsection{Plasma Citric Acid, Blood Glucose and Lactic Acid Levels}

Forty minutes after intragastric citric acid administration, citric acid concentration in blood plasma was $12.1 \mathrm{mg} / \mathrm{dL}$, higher than the $3.6 \mathrm{mg} / \mathrm{dL}$ in the distilled water ingestion group (Figure 1(a)). Blood glucose levels were also significantly elevated in the citric acid group. Glucose levels were $106 \pm 17 \mathrm{mg} / \mathrm{dL}$ in the distilled water ingestion group and $245 \pm 9 \mathrm{mg} / \mathrm{dL}$ in the citric acid group (Figure 1(b)). In contrast, blood lactic acid levels did not differ between groups $-2.8 \pm 0.4 \mathrm{mM}$ in the distilled water ingestion group versus $2.4 \pm 0.3 \mathrm{mM}$ in the citric acid group (Figure 1(c)). 


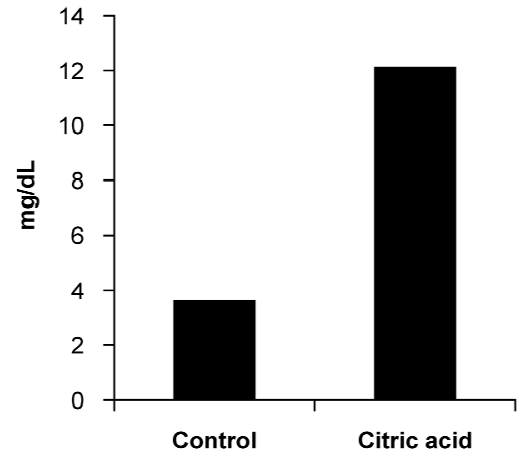

(a)

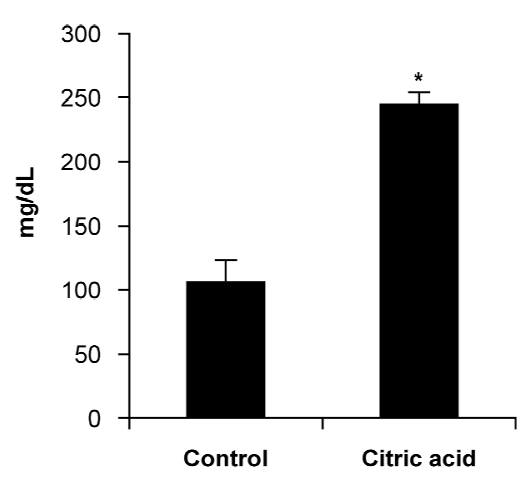

(b)

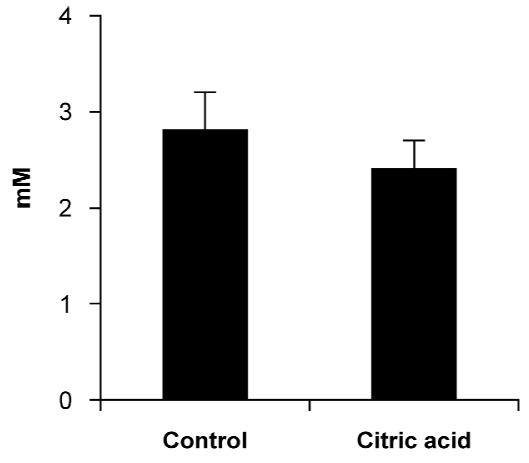

(c)

Figure 1. (a) Citric acid concentration in plasma; (b) Blood glucose levels; (c) Blood lactic acid levels.

\subsection{Transcriptional Changes: DNA Microarray Analysis}

Differences in gene expression in skeletal muscles, following citric acid ingestion, are shown in Figures 2 and 3. No differences were observed in the expression of enzymes involved in the TCA cycle (Figure 2) or in the expression of phosphofructokinase genes (Pfk: Pfkm, Pfkl, Pfkp), a rate-limiting enzyme of the glycolytic pathway (Figure 3). Also, no differences were observed in the expression of genes related to fatty acid $\beta$-oxidation or those involved in glycogenesis (data not shown). In dramatic contrast to the stable expression of these genes, phosphoenolpyruvate carboxykinase (Pck1), a major regulatory enzyme of gluconeogenesis, was elevated by more than 10-fold following the administration of citric acid (Figure 3).

\section{Discussion}

There have been numerous reports on fatigue relief and other beneficial effects of citric acid [1-3]. The mechanism responsible for these effects remains unclear; instead, all reports on anti-fatigue effect of dietary citric acid were performed as open-label trials. The results of the present study lend insight into the underlying molecular mechanism.

One hypothesized mechanism argues that citric acid ingestion suppresses lactic acid accumulation by inhibiting phosphofructokinase (Pfk), a rate-limiting enzyme of the glycolytic pathway, thereby limiting the accumulation of pyruvic acid, and, in turn, the accumulation of lactic acid $[4,6]$. This hypothesis is based on a report that Pfk activity is suppressed when citric acid, produced in the TCA cycle, moves from the mitochondria to the cytoplasm [4]. Evidence for this hypothesis is limited, but one study reported that the intake of both citric acid $(0.4$ $\mathrm{g} / \mathrm{kg}$ body weight) and glucose ( $1.5 \mathrm{~g} / \mathrm{kg}$ body weight) decreased blood lactate level 60 min following exercise in healthy adult men relative to levels measured in sub- jects that were administered only glucose [4]. Also, the production of lactate is suppressed in chicken liver cells when $10 \mathrm{mM}$ citric acid is added to culture medium [6]. However, no change in Pfk was observed in the skeletal muscle experiment in this study, suggesting that citric acid ingestion does not suppress glycolysis in skeletal muscle. In addition, there were no significant differences in blood lactic acid levels between the control and the citric acid group at 40 minutes following administration, indicating that citric acid did not suppress the accumulation of lactic acid under the conditions of this study. Since glycolysis does not intrinsically progress much under conditions of fasting without exercise, it is also possible that these conditions made it difficult for glycollysis suppression due to Pfk inhibition to appear.

Until now it has generally been thought that citric acid participated in energy production via the mitochondria where it activates the TCA cycle [7]. However, in this study, expression of enzymes involved in the TCA cycle did not differ between the skeletal muscle of the control and citric acid groups, suggesting that citric acid does not activate the TCA cycle. These results suggest that ingested citric acid does not accelerate the TCA cycle, regardless of the fact that these experiments were conducted under fasting conditions. This result also indicates the possibility that dietary citric acid is not delivered to the mitochondria.

Another mechanism proposed to explain the anti-fatigue effects of citric acid ingestion is the action of citric acid on the suppression of ketone bodies, a fatigue factor, via inhibition of fatty acid $\beta$-oxidation [10]. However, no differences were observed in the expression of genes involved in fatty acid $\beta$-oxidation in skeletal muscle (data not shown), indicating that citric acid ingestion does not suppress fatty acid $\beta$-oxidation.

On the other hand, this study showed that citric acid accelerated gluconeogenesis, a result that has not been reported previously. Expression of phosphoenolpyruvate carboxykinase (Pck1), a major regulatory enzyme of 


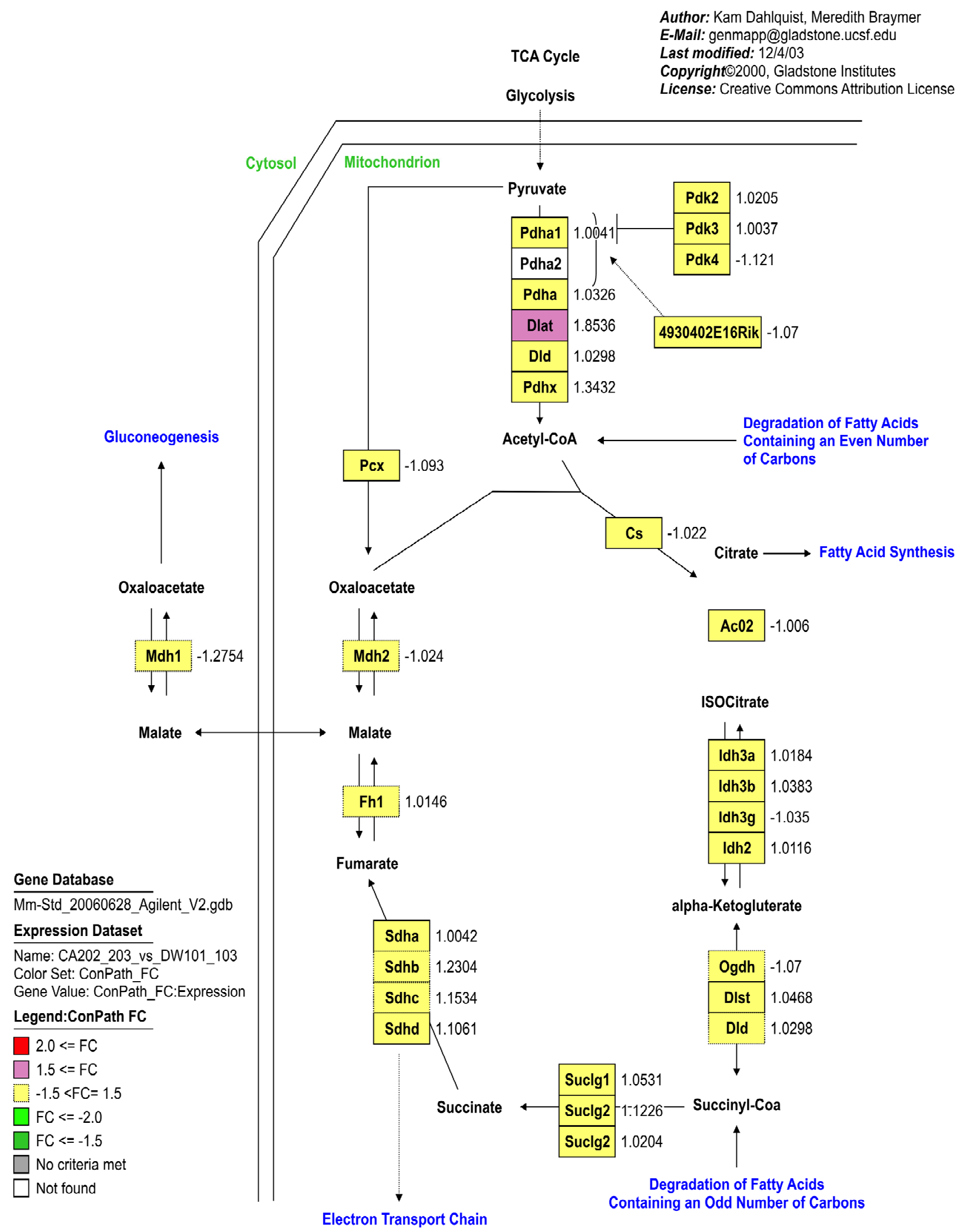

Figure 2. Pathway map of TCA cycle acquired by DNA microarray analysis. This figure shows the changes in mRNA expression in the TCA cycle. Yellow shows -1.5 - 1.5 fold change. Pink shows 1.5 - 2.5 fold change. 


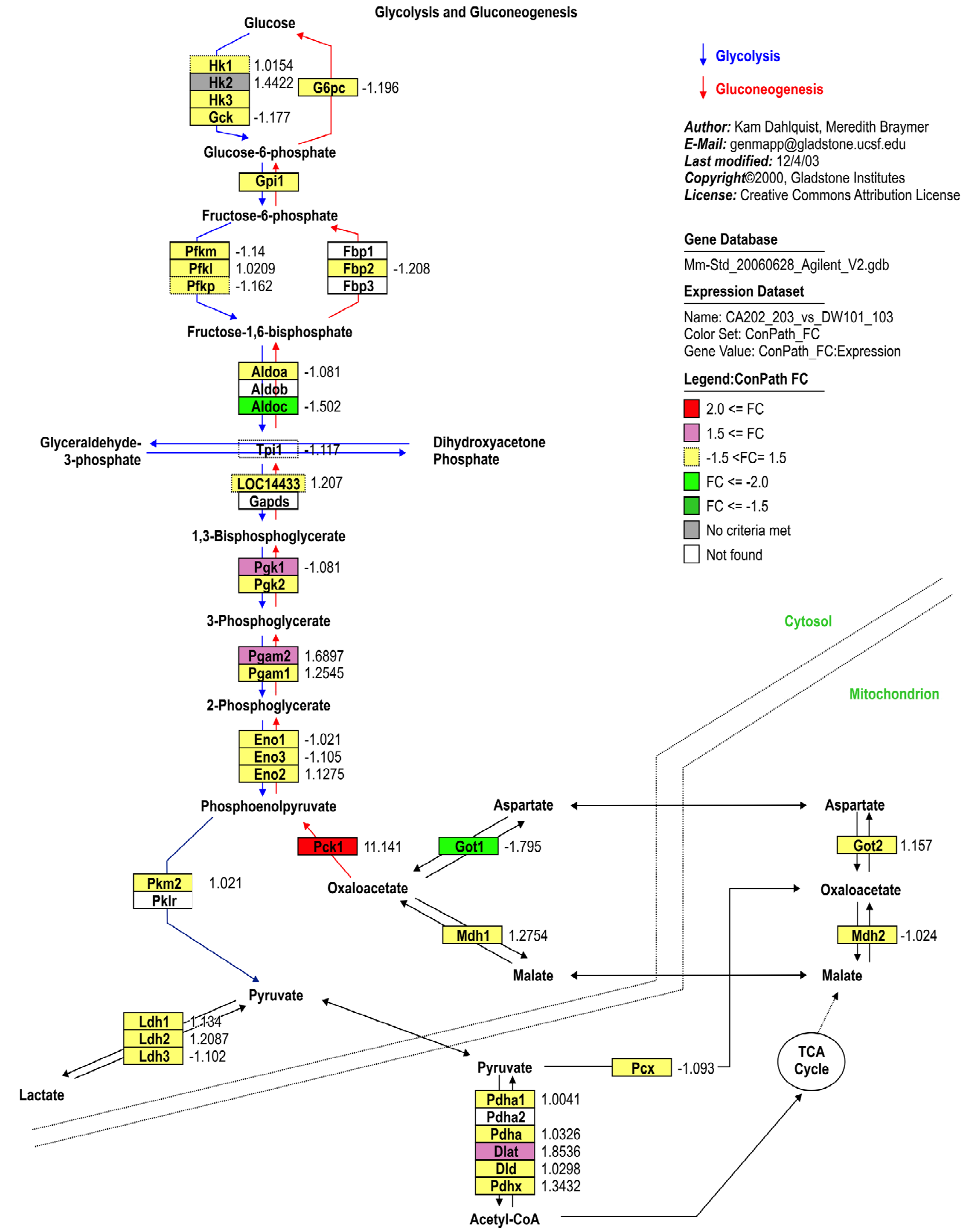

Figure 3. Pathway map of glycolysis and glugoneogenesis acquired by DNA microarray analysis. This figure shows the changes in mRNA expression in glycolysis and gluconeogenesis. Yellow shows -1.5 - 1.5 fold change. Pink shows 1.5 - 2.5 fold change. Red shows $2.5 \sim$ fold change. Green shows $-1.5--2.0$ fold change. 
gluconeogenesis, was 11.1 times greater in mouse skeletal muscle following citric acid ingestion, than in control mice. The blood glucose level in the citric acid group was $245 \pm 9 \mathrm{mg} / \mathrm{dL}$, significantly higher than the $106 \pm$ $17 \mathrm{mg} / \mathrm{dL}$ measured in the distilled water ingestion controls, suggesting that citric acid ingestion activated Pck1 and accelerated gluconeogenesis. Moreover, additional unpublished data from our lab also shows occurrence of gluconeogenesis by sole citric acid ingestion in similar experimental condition. For example, one study showed that blood glucose values were $115 \pm 4$ and $151 \pm 8$ $\mathrm{mg} / \mathrm{dL}$ for the distilled water ingestion group and citric acid ingestion group, respectively $(P=0.016)$. These results indicate that citric acid ingestion may eliminate fatigue by promoting gluconeogenesis. However, gluconeogenesis does not occur in skeletal muscle, the organ that was used for DNA microarray analysis. Therefore, we wanted to verify whether we could observe additional evidence for Pck1 activation in the liver, the main organ of gluconeogenesis.

To our knowledge, this is the first study to suggest the possibility that dietary citric acid increases gluconeogenesis.

\section{REFERENCES}

[1] O. Kajimoto, H. Saigusa, M. Hiramitsu, K. Sakaida and T. Yasuda, "The Internet Investigation about the Attenuation of Fatigue Feeling by Taking Containing Lemon Citric Acid," Japan Society of Clinical Trials and Research, Vol. 35, No. 7, 2007, pp. 821-828.

[2] C. Hausswirth, A. X. Bigard, R. Lepers, M. Berthelot and C. Y. Guezennec, "Sodium Citrate Ingestion and Muscle Performance in Acute Hypobaric Hypoxia," European Journal of Applied Physiology and Occupational Physiology, Vol. 71, No. 4, 1995, pp. 362-368. http://dx.doi.org/10.1007/BF00240418

[3] V. Oöpik, I. Saaremets, L. Medijainen, K. Karelson, T. Janson and S. Timpmann, "Effects of Sodium Citrate In- gestion before Exercise on Endurance Performance in Well Trained College Runners," British Journal of Sports Medicine, Vol. 37, No. 6, 2003, pp. 485-489. http://dx.doi.org/10.1136/bjsm.37.6.485

[4] Y. Miyake, K. Yamamoto, M. Nagasaki, N. Nakai, T. Murakami and Y. Shimomura, "The Effect of Post-Exercise Lemon Juice and Citric Acid Ingestion on Blood Lactic Acid Concentration in Humans," Japan Society of Nutrition and Food Science, Vol. 54, No. 1, 2001, pp. 2933. http://dx.doi.org/10.4327/jsnfs.54.29

[5] S. Saitoh, Y. Yoshitake and M. Suzuki, "Enhanced glycogen repletion in liver and skeletal Muscle with Citrate Orally Fed after Exhaustive Treadmill Running and Swimming," Journal of Nutritional Science and Vitaminology, Vol. 29, No. 1, 1983, pp. 45-53. http://dx.doi.org/10.3177/jnsv.29.45

[6] P. J. Pritchard and D. J. W. Lee, "The Effect of Dietary Citrate on Glycolysis in the Intestinal Mucosa and Liver of the Chicken," International Journal of Biochemistry, Vol. 3, No. 15, 1972, pp. 322-328. http://dx.doi.org/10.1016/0020-711X(72)90044-4

[7] T. Sugino, S. Aoyagi, T. Shirai, Y. Kajimoto and O. Kajimoto, "Effects of Citric Acid and L-Carnitine on Physical Fatigue," Journal of Clinical Biochemistry and Nutrition, Vol. 41, No. 3, 2007, pp. 224-230. http://dx.doi.org/10.3164/jcbn.2007032

[8] S. Yasukawa, M. Takamatsu, S. Ebisuno, S. Morimoto, T. Yoshida and T. Okawa, "Citric Acid Metabolism in Urolithiasis 1. Urinary Citric Acid Measurement Using Citrate Lyase," Japanese Urological Association, Vol. 76, No. 12, 1985, pp. 1848-1853.

[9] S. Yasukawa, S. Ebisuno, S. Morimoto, M. Uehara and T. Okawa, "An Examination of Serum Citric Acid Measurement Using Citrate Lyase," Japanese Urological Association, Vol. 82, No. 11, 1991, pp. 1748-1753.

[10] N. B. Ruderman, A. K. Saha, D. Vavvas and L. A. Witters, "Malonyl-CoA, Fuel Sensing, and Insulin Resistance," American Journal of Physiology, Vol. 276, No. 1, 1999, pp. E1-E18. 